\title{
Capturing Phase Evolution during Solvothermal Synthesis of Metastable $\mathrm{Cu}_{4} \mathrm{O}_{3}$ \\ Supporting Information
}

Zhelong Jiang, ${ }^{a}$ Shiliang Tian, ${ }^{b}$ Shuqi Lai, ${ }^{a}$ Rebecca D. McAuliffe, ${ }^{a}$ Steven P. Rogers, ${ }^{a}$ Moonsub Shim, ${ }^{a}$ and Daniel P. Shoemaker*a

${ }^{a}$ Department of Materials Science and Engineering, Frederick Seitz Materials Research Laboratory, University of Illinois at Urbana-Champaign, Urbana, Illinois 61801, United States. E-mail: dpshoema@illinois.edu

${ }^{b}$ Department of Chemistry, University of Illinois at Urbana-Champaign, Urbana, Illinois 61801, United States. 


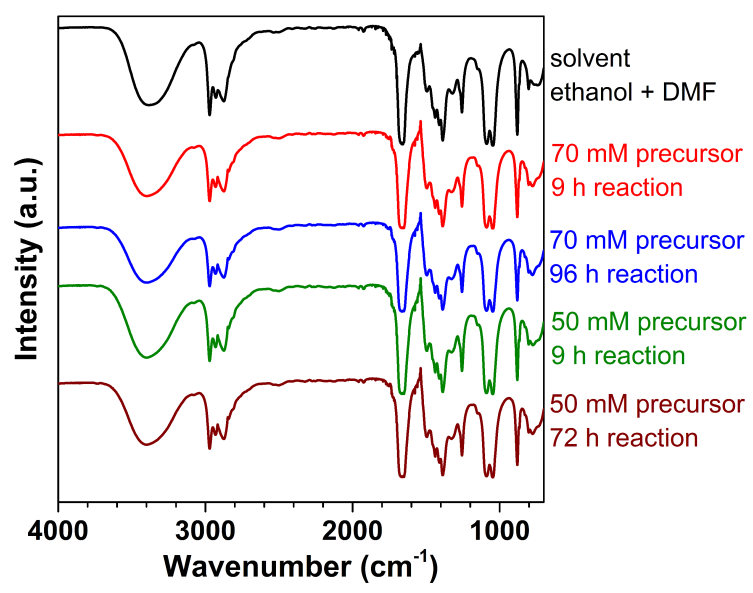

Figure S1 Attenuated total reflection Fourier transform infrared (FTIR) spectra of the solvent and product liquid phases under various reaction conditions. The FTIR spectrum of the liquid phase had no noticeable change before and after reactions, indicating no major changes in the composition of the solvent. 

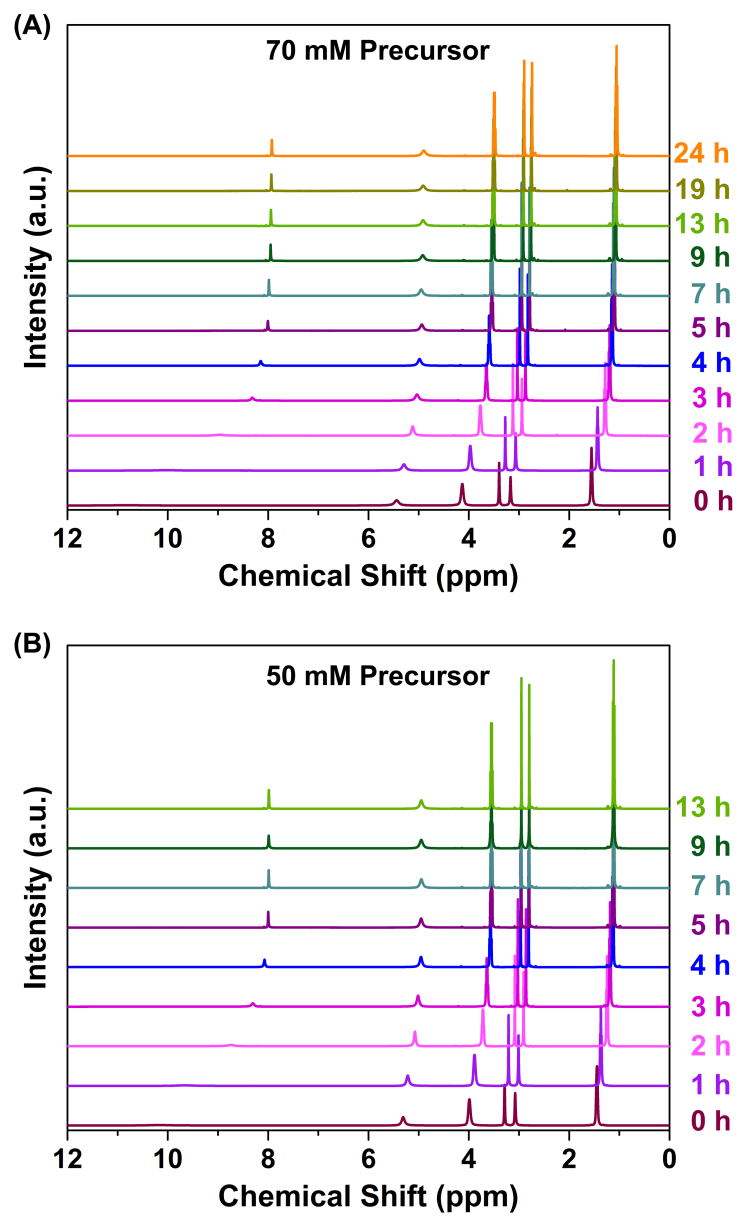

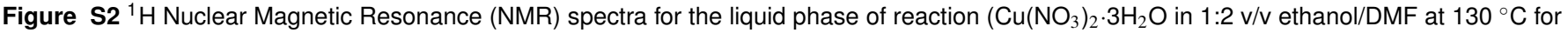
various times) with (A) $70 \mathrm{mM}$ precursor, and (B) $50 \mathrm{mM}$ precursor. No new contributions in the spectra occur as the reaction proceeds. The only change is a steady fading of the de-shielding effect from solvated $\mathrm{Cu}$ ions as they are precipitated from the solution.

The major peaks in all ${ }^{1} \mathrm{H}$ NMR spectra can be assigned to either ethanol or DMF. Despite having the same number of peaks, two systematic changes were found in the NMR spectra with respect to reaction time. The first is the continued drift of the chemical shift to upfield with reaction time, and the second is the narrowing of the NMR peaks with reaction time. Both effects were most drastic at the initial phases of the reaction and stagnated after 5 hours of reaction for both precursor concentrations studied.

The behavior of the NMR spectra indicated de-shielding of all solvent hydrogen atoms when the solvent molecules (ethanol and DMF) participated in the solvation of $\mathrm{Cu}\left(\mathrm{NO}_{3}\right)_{2} \cdot 3 \mathrm{H}_{2} \mathrm{O}$, but the de-shielding effect waned with reaction time. The initial de-shielding (upfield chemical shift) implies chemical environment change with the addition of $\mathrm{Cu}\left(\mathrm{NO}_{3}\right)_{2} \cdot 3 \mathrm{H}_{2} \mathrm{O}$, whose interactions with the solvent species led to copper ion solvation. It is a common observation for all ${ }^{1} \mathrm{H}$ NMR peaks in a system to change position and linewidth due to solvent-solute interactions, especially with transition metal ions. ${ }^{1}$ The degree of influence on each peak, as well as the directions of chemical shift, however, depend on the specific combination of metal centers and the solvent species. The observed waning of the de-shielding effect implies that the responsible species (i.e. $\mathrm{Cu}$ ions) were precipitated from the liquid with reaction time. After 5 hours of reaction, the sample NMR spectra were close to that of pristine solvent, indicating that the majority of the $\mathrm{Cu}$ ions were depleted from the liquid by this time.

NMR did not reveal the formation of any distinct organic species, although the presence of non- $\mathrm{H}$-containing species or compounds that were stable only at solvothermal reaction temperature cannot be ruled out. 
(A)

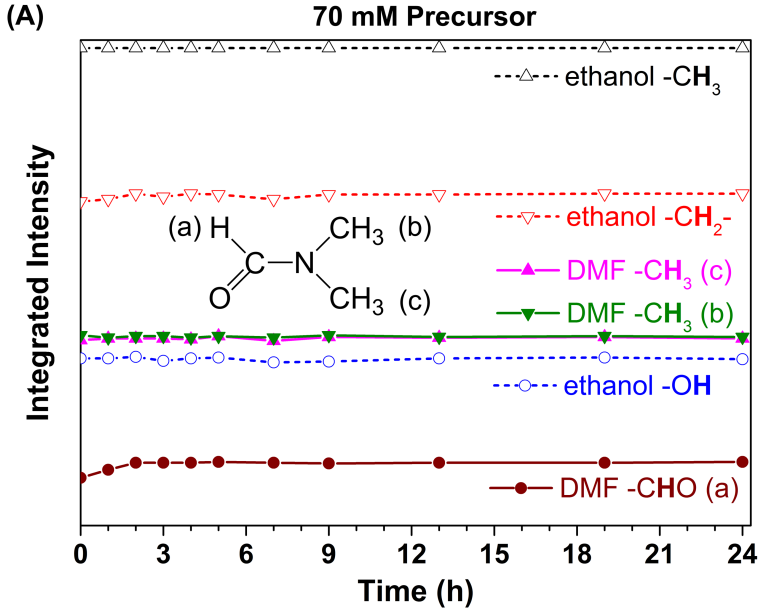

(B) $50 \mathrm{mM}$ Precursor

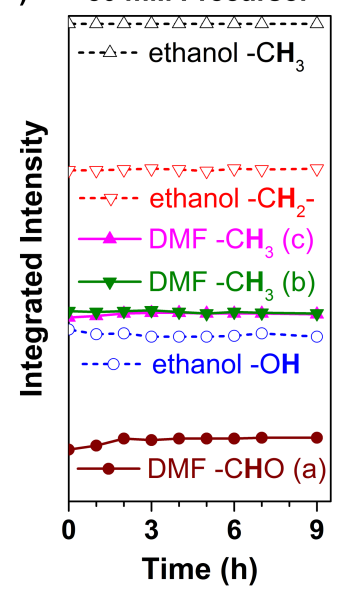

Figure S3 Changes of the integrated intensity for the various ${ }^{1} \mathrm{H}$ NMR peaks with time for (A) $70 \mathrm{mM}$ precursor series and (B) $50 \mathrm{mM}$ precursor series. The low values of the DMF - $\mathrm{CHO}$ integrated intensity at short reaction time were due to the peaks being extremely low and broad, making integration unreliable. The integrated intensity was normalized with respect to the ethanol $-\mathrm{CH}_{3}$ intensity. The integrated NMR intensity did not change with reaction time, implying a steady solvent composition throughout the reaction.

Integration of the NMR peaks indicated a consistent ratio between DMF and ethanol through the course of the reaction, signaling a relatively stable solvent environment for this reaction system. 

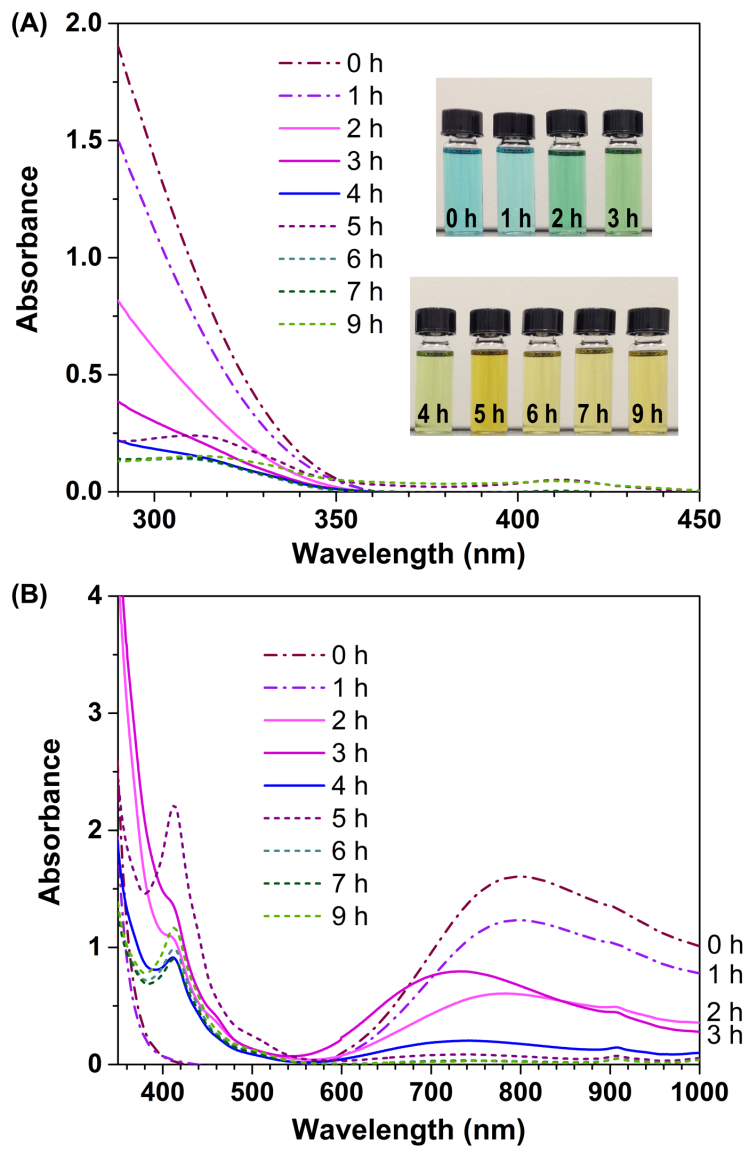

Figure S4 UV-vis spectra for the liquid phase after reaction $\left(50 \mathrm{mM} \mathrm{Cu}\left(\mathrm{NO}_{3}\right)_{2} \cdot 3 \mathrm{H}_{2} \mathrm{O}\right.$ reacted in $1: 2 \mathrm{v} / \mathrm{v}$ ethanol/DMF at $130{ }^{\circ} \mathrm{C}$ for various times): $(\mathrm{A})$ diluted samples (to $4 \mathrm{vol} \%$ with ethanol), (B) undiluted samples. Inset in panel A are photos of the corresponding liquid phase after reactions.

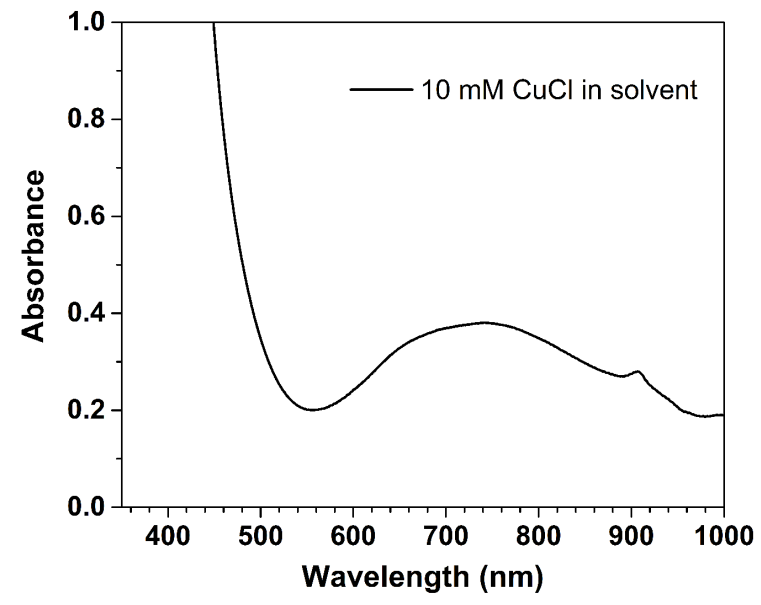

Figure S5 UV-vis spectrum of $10 \mathrm{mM} \mathrm{CuCl}$ in 1:2 v/v ethanol/DMF. 


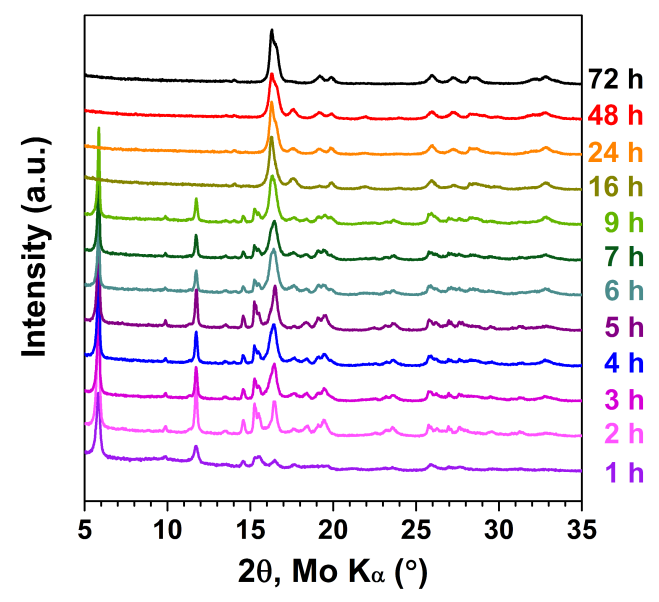

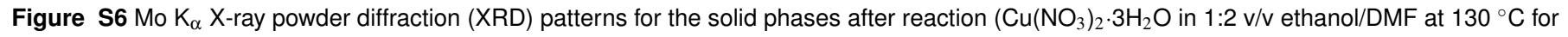
various times) with $50 \mathrm{mM}$ precursor. 
(A)
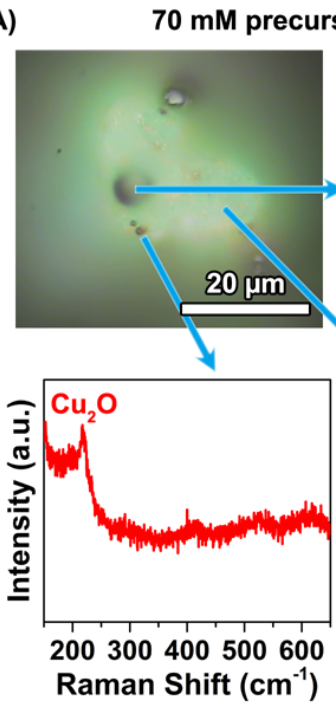

(C)

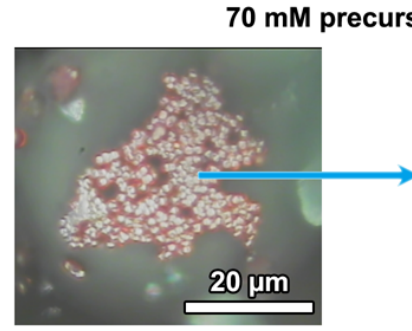

(D)

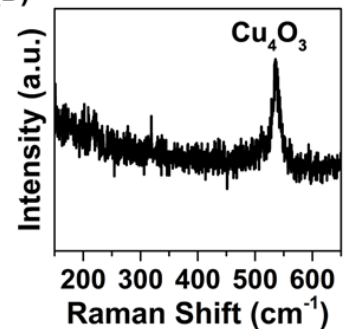

(B) $50 \mathrm{mM}$ precursor $-4 \mathrm{~h}$
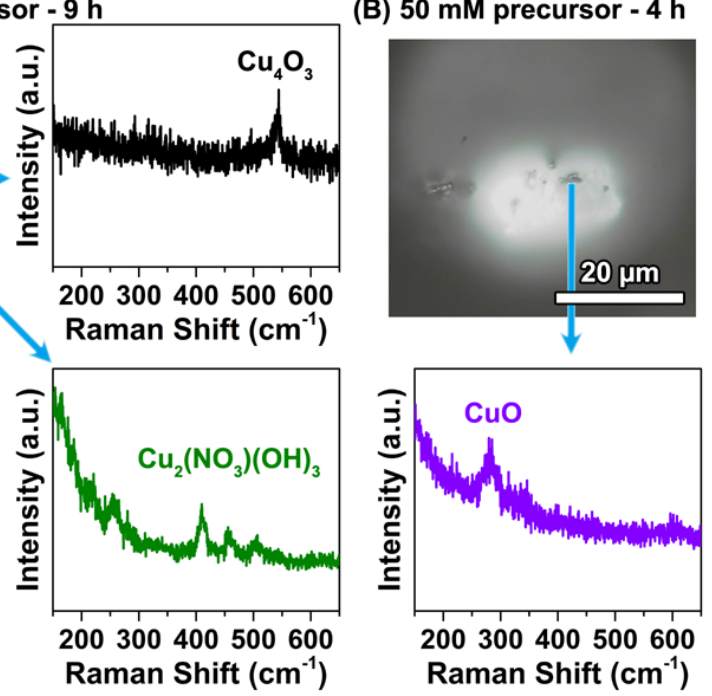

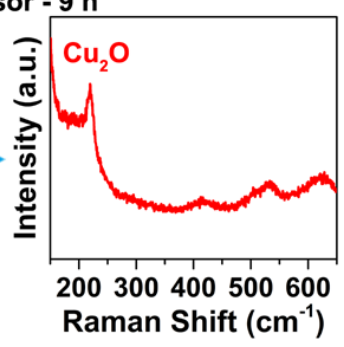

$70 \mathrm{mM}$ precursor $-24 \mathrm{~h}$
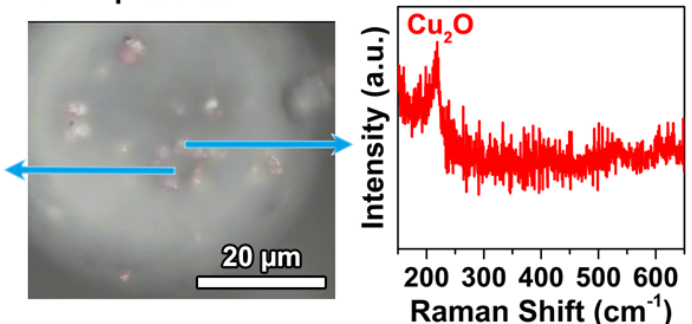

Figure S7 Visible light microscopy images and the corresponding micro-Raman spectra of (A) $70 \mathrm{mM}$ precursor $9 \mathrm{~h}$, and (B) $50 \mathrm{mM}$ precursor $4 \mathrm{~h}$ samples. They demonstrate that $\mathrm{Cu}_{2}\left(\mathrm{NO}_{3}\right)(\mathrm{OH})_{3}$ appeared emerald, $\mathrm{Cu}_{2} \mathrm{O}$ red, $\mathrm{Cu}_{4} \mathrm{O}_{3}$ and $\mathrm{CuO}$ black in visible light microscopy images. Visible light microscopy images and the corresponding micro-Raman spectra of $(C)$ the self-assembled film seen in $70 \mathrm{mM}$ precursor $9 \mathrm{~h}$ sample, and (D) the spheres with corrugated surface seen in $70 \mathrm{mM}$ precursor $24 \mathrm{~h}$ sample. This confirms that the self-assembled films were $\mathrm{Cu}_{2} \mathrm{O}$ and that the corrugated spheres were composed of $\mathrm{Cu}_{4} \mathrm{O}_{3}$ core and $\mathrm{Cu}_{2} \mathrm{O}$ shell. 

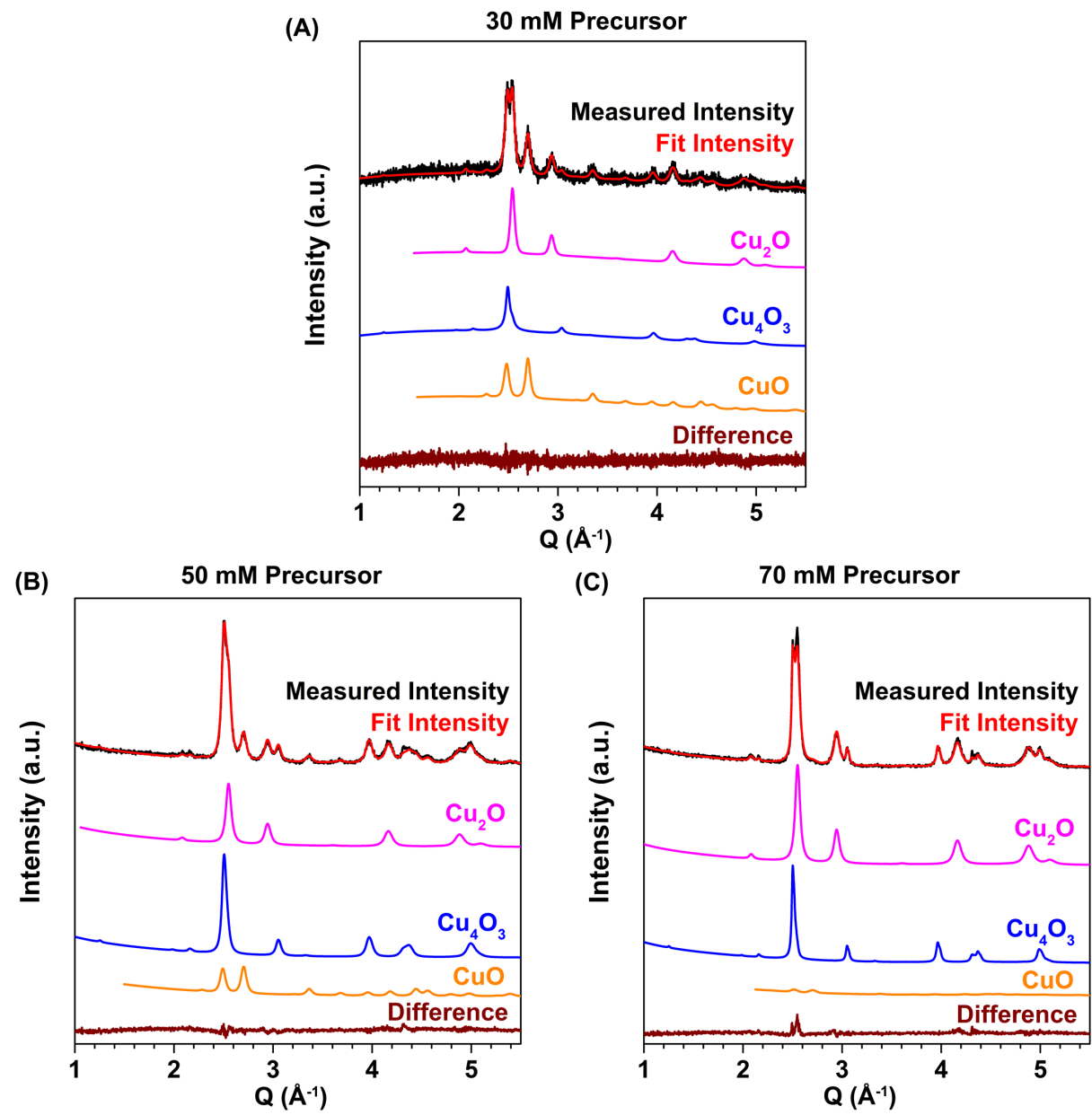

Figure S8 Rietveld refinement results of XRD patterns for solid precipitates collected after reacting (A) $30 \mathrm{mM}$, (B) $50 \mathrm{mM}$, and (C)70 mM $\mathrm{Cu}\left(\mathrm{NO}_{3}\right)_{2} \cdot 3 \mathrm{H}_{2} \mathrm{O}$ in $1: 2 \mathrm{v} / \mathrm{v}$ ethanol/DMF at $130{ }^{\circ} \mathrm{C}$ for $48 \mathrm{~h}$. Panel A was collected with reflection geometry using Siemens Bruker D-5000 with Cu K $\alpha$ $\mathrm{X}$-ray source, whereas panels $\mathrm{B}$ and $\mathrm{C}$ were collected with transmission geometry using Bruker D8 ADVANCE with Mo $\mathrm{K}_{\alpha}$ source. They demonstrated the positive correlation between $\mathrm{Cu}\left(\mathrm{NO}_{3}\right)_{2} \cdot 3 \mathrm{H}_{2} \mathrm{O}$ concentration and copper valence reduction.

\section{References}

1 C. N. Banwell, Fundamentals of Molecular Spectroscopy, McGraw-Hill, London, New York, 2nd edn., 1972. 